\title{
Combined Hydrogen Production and Storage with Subsequent Carbon Crystallization
}

\author{
Angela D. Lueking*, Humberto R. Gutierrez, Dania A. Fonseca, Deepa L. Narayanan, Dirk Van \\ Essendelft, Puja Jain, Caroline E. B. Clifford \\ The Pennsylvania State University; University Park, PA \\ RECEIVED DATE; adl11@psu.edu
}

\section{Supporting Information}

Materials: The coal used is Buck Mountain PSOC-1468, (abbreviated as BMT) from the Penn State University coal sample bank. BMT is an anthracite coal from the bottom of the Llewellyn formation the Buck Mountain Seam, collected from Luzerne Co., PA. The BMT has a low volatile matter content (3.65 wt \%, dry) and high fixed carbon content (89.52 wt \%, dry). The ash content of the coal precursor is relatively low for a naturally occurring coal (6.6\%), consisting primarily of naturally occurring minerals; neutron activation analysis (NAA) of the coal precursor indicated traces of Aluminum, Antimony, Arsenic, Barium, Bromine, Cerium, Chromium, Hafnium, Iron, Lanthanum, Magnesium, Potassium, Scandium and Tungsten, as reported previously. The amount of silicon present in the coal precursor is not currently known, as differentiation between $\mathrm{Al}$ and $\mathrm{Si}$ is difficult via NAA. For this study, no attempt was made to dissolve the natural mineral matter of the BMT coal via acid treatment prior to the ball milling, as milling materials (i.e. $\mathrm{Fe}, \mathrm{Ni}, \mathrm{Cr}$ from stainless steel) are transferred to the sample during the high energy ball milling process.

Synthesis: A Fritsch Pulveristte LC-106A with stainless steel components (316 SS) was used to ball mill the samples at $400 \mathrm{rpm}$ for 80 hours with a cyclohexene (JT Baker, 99\%) wetting agent added at a 3.3 milliliter per gram of coal ratio. All milling occurred under a 1 bar argon atmosphere to minimize oxidation effects and water contamination during processing. The entire milling process was conducted intermittently ( 10 minutes on followed by 5 minutes off) to minimize heating effects during milling. A portion of the samples was subjected to a subsequent thermal anneal at $1400^{\circ} \mathrm{C}$ for $3 \mathrm{~h}$ under $1000 \mathrm{~mL} / \mathrm{min}$ of argon. Select samples were purified using: $4 \mathrm{M} \mathrm{HCl}$ for $24 \mathrm{~h}$ at room temperature, extensive washing with deionized water, a $10 \mathrm{M} \mathrm{NaOH}$ treatment for $24 \mathrm{~h}$ at room temperature, then extensive washing with deionized water. BMT refers to the Buck Mountain coal, BMT* refers to Buck Mountain Coal milled for 80 hours in cyclohexene, and BMT*-1400 refers to the sample after a 1400 ${ }^{\circ} \mathrm{C}$ thermal anneal followed by the $\mathrm{HCl}$ and $\mathrm{NaOH}$ purification.

Presented in the supplementary information are samples modified as follows: procedure: $\mathrm{BMT}^{* \text { dry }}$ is a sample milled without cyclohexene, with all other milling conditions as stated above. $\mathrm{BMT}^{* \mathrm{Ar}}$ is a second preparation of the sample milled with cyclohexene, stored in argon after milling. Once milled, this sample was unloaded under a blanket of argon (UHP grade, 99.999\% purity) in a glove box, then stored in a sealed pack until it was unloaded and transferred (in air) to the TG-MS for analysis. The oxygen content of the transfer box was monitored to be below $2 \%$ by using an Oxor II $(0-25.5 \%)$ gas analyzer from Bacharach at all times. Several samples were mixed with cyclohexene directly prior to TG-MS measurements to test whether cyclohexene would dehydrogenate in the TG-MS: $\mathrm{BMT}+\mathrm{CH}$, Graphite $+\mathrm{CH}, \mathrm{BMT}^{*}+\mathrm{CH}$ refer to the BMT coal precursor, graphite, and the ball milled BMT* all mixed with cyclohexene in the ratio of $3.3 \mathrm{ml} / \mathrm{g}$ immediately prior to TGMS measurements.

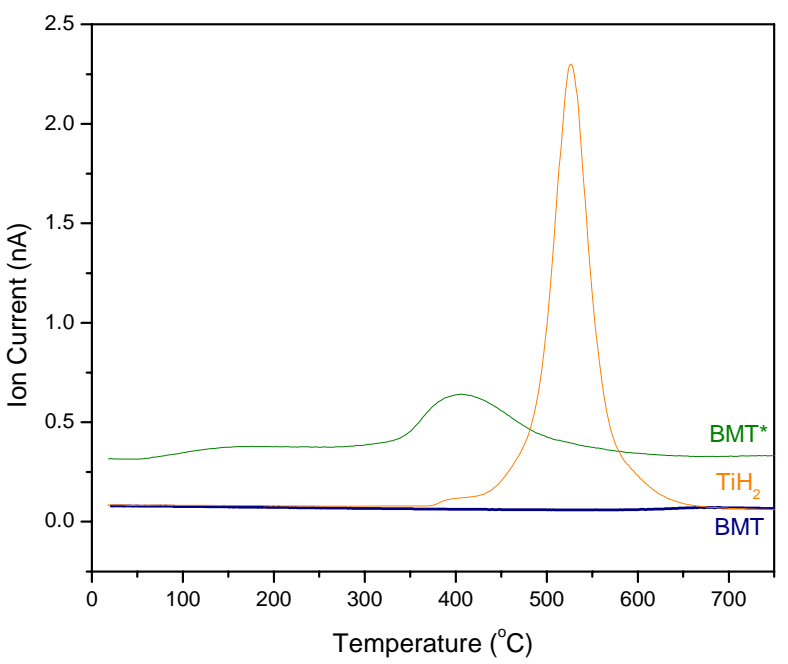

Figure SI-1: A comparison of the hydrogen $(\mathrm{m} / \mathrm{z}=2)$ baseline for BMT* relative to a selected $\mathrm{TiH}_{2}$ run used in the calibration curve and the untreated coal precursor, BMT.

Characterization: Electron micrographs were obtained via transmission electron microscopy (TEM) on a JEOL 2010F at $200 \mathrm{kV}$. Energy-dispersive X-ray (EDX) spectra were taken on select samples during TEM analysis. Raman spectroscopy was done on a Renishaw inVia spectrometer with a confocal Leica DM LM microscope and a Peltier cooled RnCam dd-CCD with a frequency doubled $488 \mathrm{~nm}$ argon ion laser to obtain $244 \mathrm{~nm}$ UV.

Hydrogen Evolution: A Thermogravimetric Analyzer, TGA 2050 interfaced to a ThermoStar Mass Spectrometer was used to characterized the thermal desorption of hydrogen from the samples. UHP Argon was flowed as a carrier gas at $100 \mathrm{ml} / \mathrm{min}$. Samples were transferred to the TG-MS with air exposure then heated up from room temperature to $1000{ }^{\circ} \mathrm{C}$ at $10{ }^{\circ} \mathrm{C} / \mathrm{min}$. Data to only $750{ }^{\circ} \mathrm{C}$ is presented in the main paper, as hydrogen evolution above $750{ }^{\circ} \mathrm{C}$ may be due to gasification of the carbon with trace water in the system. During the measurement, the pressure inside the vacuum system (quadrupole mass spectrometer) was in the range of $1.7 \times 10^{-6}$ mbar. BMT* samples were stored in air prior to measurement; the BMT*Ar sample was stored in argon prior to measurement but had brief air exposure upon sample transfer to the TG-MS. The TG-MS 
for BMT* was collected after 3, 30, and 76 days after preparation (Figure $1 \mathrm{a}-\mathrm{c}$, respectively). BMT ${ }^{* \mathrm{Ar}}$ was collected 10 days after preparation. The storage times were due to scheduling of the TG-MS. In order to quantify the hydrogen released from the samples, the hydrogen signal was calibrated

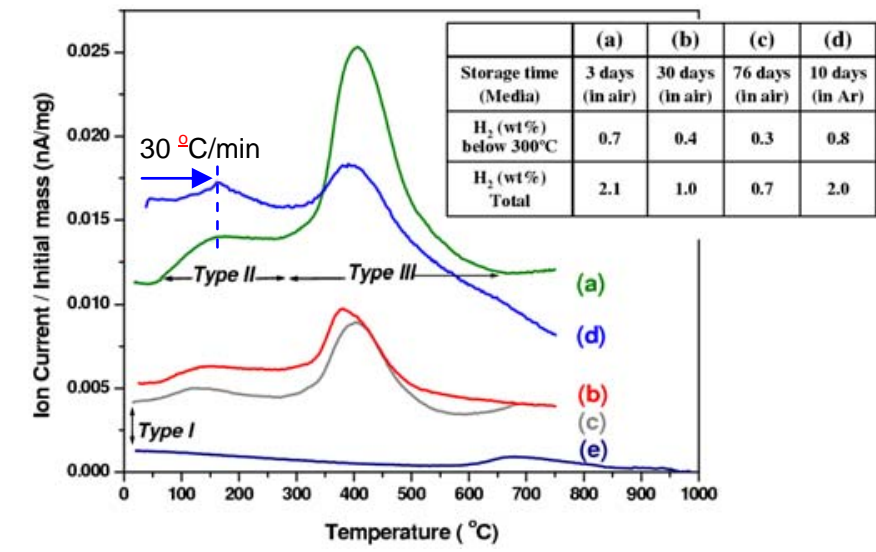

Figure SI-2: A second preparation of BMT* (d) had the same qualitative hydrogen evolution compared to the first preparation of BMT* (a-c). The peak at $150{ }^{\circ} \mathrm{C}$ is due to a modified temperature profile for this run.

using $\mathrm{TiH}_{2}$ as a standard, assuming the $\mathrm{TiH}_{2}$ evolves 4.0 wt.\% of hydrogen (verified with the gravimetric analyzer). The calibration curve was constructed by plotting the integrated ion current over all temperatures for different quantities of $\mathrm{TiH}_{2}$.

In addition to the hydrogen signal at $\mathrm{m} / \mathrm{z}=2$, other mass spectrometer signals discussed here are assigned to benzene $(\mathrm{m} / \mathrm{z}=78)$ and cyclohexene $(\mathrm{m} / \mathrm{z}=82)$. Cyclohexene does not have MS lines at $\mathrm{m} / \mathrm{z}=78$, and neither benzene nor cyclohexene have MS lines at $\mathrm{m} / \mathrm{z}=2$.

Baseline stability of quadrupole mass spectrometer: The $\mathrm{TiH}_{2}$ used as a calibration standard was run on different days, and showed negligible change in baseline compared to the BMT* samples. The baseline observed for $\mathrm{TiH}_{2}$ standards was approximately the same as the raw coal precursor (BMT), graphite, and samples ball milled without cyclohexene. Therefore, QMS signal drift is not the cause for the changes of baseline observed in the samples ball milled with cyclohexene $\left(\mathrm{BMT}^{*}\right)$. The baseline of $\mathrm{BMT}^{*}$ is compared to the raw coal (BMT) and one example from the $\mathrm{TiH}_{2}$ calibration curve in Figure SI-1. All samples reported were performed in the period of $\sim 10$ weeks on the TG-MS (Table 1 ). The baseline of $\mathrm{TiH}_{2}$,

Table 1: TG-MS data to show baseline fluctuations with sample, time, and initial sample mass. Data is listed sequentially, based on the date collected.

\begin{tabular}{|c|c|c|}
\hline Sample (in order run) & $\begin{array}{l}\text { Initial Ion current } \\
\text { for } m / z=2(n A)\end{array}$ & Initial mass (mg) \\
\hline BMT* (3days) & 0.3167 & 23.15 \\
\hline BMT & 0.079 & 21.9 \\
\hline $\mathrm{TiH}_{2}(1)$ & 0.083 & 8.05 \\
\hline $\mathrm{TiH}_{2}(2)$ & 0.086 & 23.48 \\
\hline $\mathrm{TiH}_{2}(3)$ & 0.078 & 55.6 \\
\hline $\mathrm{BMT}^{* \mathrm{Ar}}$ & 0.1919 & 10.6 \\
\hline BMT* (30 days) & 0.1464 & 19.11 \\
\hline Graphite $+\mathrm{CH}^{\mathrm{a}}$ & 0.075 & 12.29 \\
\hline $\mathrm{BMT}^{* d r y}+\mathrm{CH}^{\mathrm{a}}$ & 0.0465 & 11.39 \\
\hline BMT* (76 days) & 0.1091 & 16.79 \\
\hline \multicolumn{3}{|c|}{$\begin{array}{l}\text { "Samples with cyclohexene added directly prior to TG-MS are } \\
\text { denoted with "+CH". The initial mass of these samples includes the } \\
\text { added cyclohexene. }\end{array}$} \\
\hline
\end{tabular}

and the BMT coal precursor varied within 0.047-0.086 nA; the baseline for graphite with added cyclohexene was $0.075 \mathrm{nA}$, whereas the baseline for $\mathrm{BMT}^{*}$ dry was $0.0465 \mathrm{nA}$. The baseline for BMT* samples ranged from 0.11-0.32 nA, with the baseline correlating to sample age: $0.32 \mathrm{nA} 3$ days after preparation, $0.1464 \mathrm{nA} 30$ days after preparation, $0.1091 \mathrm{nA} 76$ days after preparation. Several samples in which cyclohexene was added immediately prior to the TG-MS run (i.e. Graphite+CH and $\mathrm{BMT}^{*}$ dry $+\mathrm{CH}$ ) has a baseline comparable to the BMT and $\mathrm{TiH}_{2}$ runs. An immediate increase in the hydrogen signal was also observed on a separate quadrupole mass spectrometer (VG Quadrupole, Sensorlab), immediately after loading BMT*.

Additional Sample Preparation: A second sample $\left(\mathrm{BMT}^{*}{ }^{\mathrm{Ar}}\right)$ was prepared to determine the reproducibility of the hydrogen evolution, and assess the effect of air exposure during storage. The TGA procedure for this sample was modified slightly as it was performed in a separate collection of samples: up to $150{ }^{\circ} \mathrm{C}$, the temperature was ramped at $30{ }^{\circ} \mathrm{C} / \mathrm{min}$; after
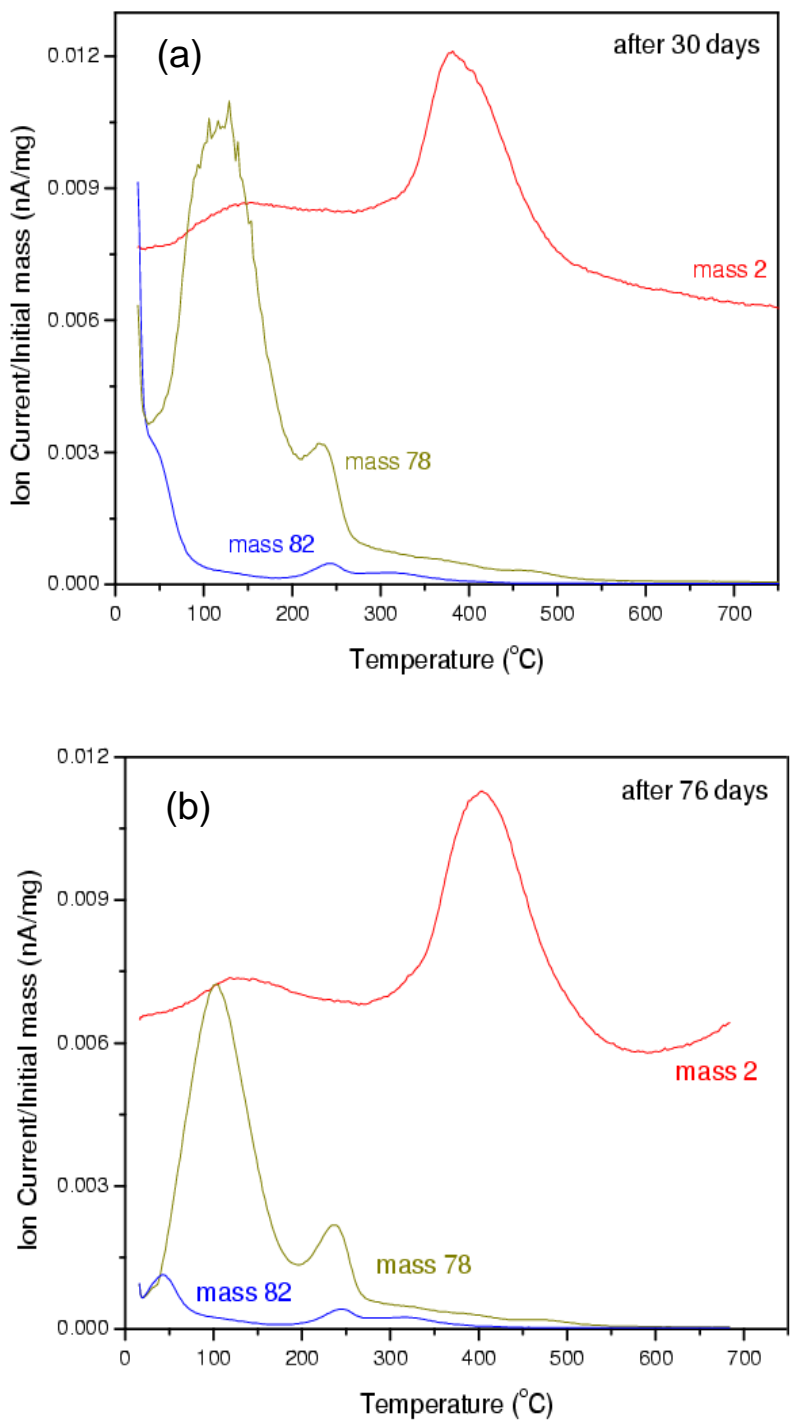

Figure SI-3: The evolution of cyclohexene $(\mathrm{m} / \mathrm{z}=82)$, benzene $(\mathrm{m} / \mathrm{z}=78)$, and hydrogen $(\mathrm{m} / \mathrm{z}=2)$, for BMT* prepared (a) 30 and (b) 76 days prior to the measurement. These graphs correspond to Figures $1 \mathrm{~b}$ and $1 \mathrm{c}$ in the main paper. The hydrogen baseline signal is not fully proportional to the magnitude of the other signals (see text). 
$150{ }^{\circ} \mathrm{C}$, the temperature was ramped at $10{ }^{\circ} \mathrm{C} / \mathrm{min}$ as in the previous case. The sample had the same qualitative behavior as the first preparation, with the exception of a peak at $150{ }^{\circ} \mathrm{C}$ that was brought about by the change in ramping rate at $150{ }^{\circ} \mathrm{C}$. The hydrogen evolution from this sample is comparable to the first preparation of BMT* after storage in air (See Figure SI-2).

Evidence for Dehydrogenation of Cyclohexene: On-going work is underway to elucidate the mechanism of hydrogen production and trapping. Currently, we have evidence for the evolution of benzene by tracking $\mathrm{m} / \mathrm{z}=78$; we have assigned the $\mathrm{m} / \mathrm{z}=78$ peak to benzene although other hydrocarbons and decomposition products may be evolving from the sample. In Figure SI-3 we show the benzene and cyclohexene evolution that accompanies the hydrogen evolution presented in Figure 1 of the main paper. Figure SI-3a corresponds to Figure $1 \mathrm{~b}$ and is BMT* 30 days of preparation; likewise, Figure SI-3b corresponds to Figure $1 \mathrm{c}$ and is 76 days after preparation. The $\mathrm{m} / \mathrm{z}=78$ data was not collected for the sample corresponding to Figure 1a, and is thus not shown. The hydrogen evolution profiles are discussed in the main paper, and will not be discussed again here. The data indicate that cyclohexene remains in the sample after ball milling, but the cyclohexene evolution has decreased significantly from 30 to 76 days. 76 days after preparation, a small amount of cyclohexene evolves from the BMT* sample with slight heating. Despite the decreased cyclohexene signal, the hydrogen evolution from the two samples is quite similar: Below $300{ }^{\circ} \mathrm{C}, 0.4 \mathrm{wt} \%$ and 0.3 $\mathrm{wt} \%$ evolve for the 30 and 76 day samples, respectively. Below $750{ }^{\circ} \mathrm{C}, 1.0 \mathrm{wt} \%$ and $0.7 \mathrm{wt} \%$ hydrogen evolve for the 30 and 76 day samples, respectively (see Figure 1). We thus cannot attribute hydrogen evolution solely to cyclohexene dehydrogenation within the TG-MS. In a separate work (reference 26), we have observed similar hydrogen evolution from samples measured with an alternate TG-MS set-up.

Cyclohexene Addition: Also evaluated were several carbonbased samples with cyclohexene added immediately prior to the TG-MS run. Cyclohexene was added at the same ratio (3.3 $\mathrm{ml} / \mathrm{g}$ ) used in the preparation of BMT*. The carbons included graphite, $\mathrm{BMT}^{*}$, and $\mathrm{BMT}^{* \text { dry }}$ (see Table 1 ). $\mathrm{BMT}^{* \text { dry }}$ is a modified version of BMT* with no cyclohexene added during milling. These samples did not have an increased hydrogen baseine hydrogen evolution, despite the addition of cyclohexene (see Table 1). The samples do, however, have evidence of benzene evolution $(\mathrm{m} / \mathrm{z}=78)$, suggesting cyclohexene dehydrogenation may occur within the TG-MS. The dehydrogenation may be catalyzed by either system components or the carbon samples. An example of such behavior is shown for $\mathrm{BMT}^{*}{ }^{*}+\mathrm{CH}$ in Figure SI-4. Below 100 ${ }^{\circ} \mathrm{C}$, the benzene signal is accompanied by a hydrogen signal, with similar temperature profiles. In other words, the qualitative nature of the signals are virtually identical for $\mathrm{m} / \mathrm{z}=$ 2, 78, and 82. A high temperature hydrogen peak is observed for most carbon based sample, and we attribute to coal gasification with trace water from the system. As the hydrogen and benzene are observed at the same temperature, the hydrogen and benzene evolve at the same time, suggesting cyclohexene dehydrogenation occurs within the TG-MS. This is dissimilar to the BMT* samples (Figure SI-3) in which the benzene $(\mathrm{m} / \mathrm{z}=78)$ and hydrogen $(\mathrm{m} / \mathrm{z}=2)$ evolution do not occur at the same temperatures. Most notable is the absence of a Type III hydrogen peak $\left(\sim 400{ }^{\circ} \mathrm{C}\right)$ that is characteristic of carbon sample ball milled in hydrogen (see discussion in main text of paper). This provides evidence that the $\sim 400{ }^{\circ} \mathrm{C}$ hydrogen evolution is formed via hydrogen trapping in the ball mill, similar to previous reports for carbons ball milled in high pressure hydrogen.

The following observations account for the statement that cyclohexene dehydrogenation cannot fully account for the observed hydrogen evolution: (1) the lack of correspondence between benzene and hydrogen evolution in Figure SI-3, most notably the Type III hydrogen evolution, (2) the magnitude of hydrogen evolution from BMT* samples that does not fully correlate to cyclohexene (or benzene) evolution from the samples; and (3) an increased baseline is observed only for BMT* samples.

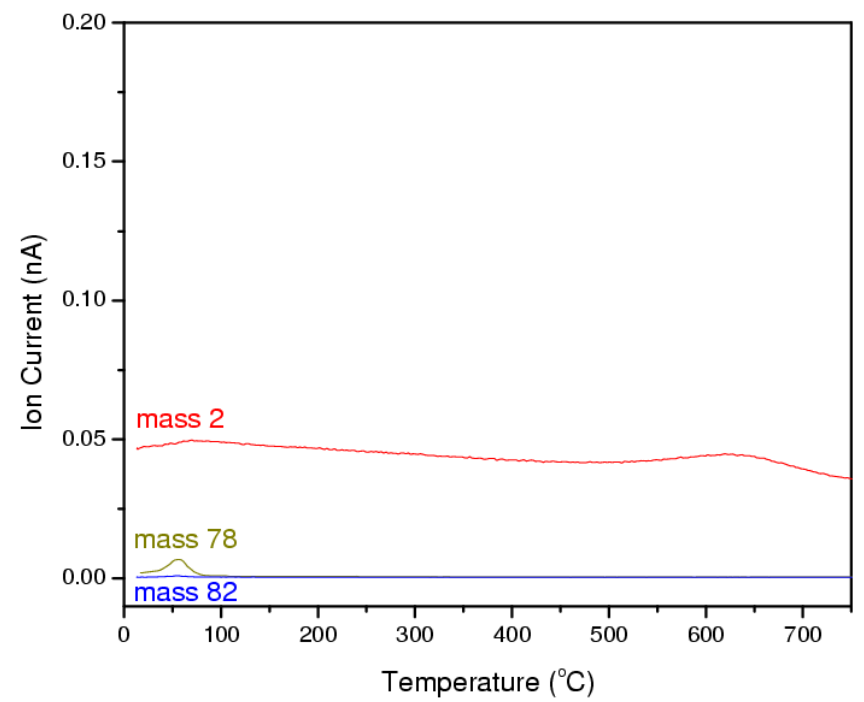

Figure SI-4: The evolution of hydrogen $(\mathrm{m} / \mathrm{z}=2)$, benzene $(\mathrm{m} / \mathrm{z}=78)$ and cyclohexene $(\mathrm{m} / \mathrm{z}=82)$ from $\mathrm{BMT}^{*}{ }^{*}+\mathrm{CH}$; cyclohexene is added directly prior to the TG-MS, but not to the ball mill. 
